\title{
Correlation between National Peak HIV Prevalence and Concurrency, STI Treatment Capability, Condom Use and Circumcision: An Ecological Study
}

\author{
Chris R. Kenyon*, Jozefien Buyze \\ HIV/STI Unit, Institute of Tropical Medicine, Antwerp, Belgium \\ Email: ${ }^{*}$ kkenyon@itg.be
}

Received 2 April 2014; revised 2 May 2014; accepted 25 May 2014

Copyright (C) 2014 by authors and Scientific Research Publishing Inc.

This work is licensed under the Creative Commons Attribution International License (CC BY). http://creativecommons.org/licenses/by/4.0/

cc) (i) Open Access

\section{Abstract}

Background: The extent of the differential spread of HIV around the world remains incompletely explained. This paper examines the extent to which five explanatory variables (circumcision prevalence, condom usage, STI treatment coverage, number of sex partners, partner concurrency) are correlated with peak HIV prevalence rates at a country level. Methods: We performed linear regression analysis to measure the association between each of the independent variables and the national peak HIV prevalence rates for 15 - 49 years old. Results: Our analysis shows a strong positive association between peak HIV prevalence and the prevalence of partner concurrency $(\mathrm{rho}=$ 0.853; $P=0.001$ ). There was no association between peak HIV prevalence and circumcision prevalence $($ rho $=0.118 ; P=0.161)$, condom usage $($ rho $=0.048 ; P=0.794)$, STI treatment coverage (rho $=0.143 ; P=0.136$ ) and number of sex partners ( $r$ o $=0.134 ; P=0.298$ ) at a global level. There was however a strong negative association between peak HIV prevalence and circumcision prevalence when the analysis was limited to countries within sub Saharan Africa (rho = -0.659; $P$ $=0.000$ ). Sub Saharan Africa had the second and third highest circumcision rates in the world when the circumcision prevalence thresholds were set at $80 \%$ and $20 \%$ respectively. Conclusions: Differences in the prevalence of circumcision likely influence differential peak HIV prevalence within sub Saharan Africa but are implausible causes for the higher HIV prevalence in this region. The close association found between concurrency and HIV prevalence requires replication in further studies.

\section{Keywords}

HIV, Sexual Network, Epidemiology, Peak HIV Prevalence, Ecological

\footnotetext{
${ }^{*}$ Corresponding author.
}

How to cite this paper: Kenyon, C.R. and Buyze, J. (2014) Correlation between National Peak HIV Prevalence and Concurrency, STI Treatment Capability, Condom Use and Circumcision: An Ecological Study. World Journal of AIDS, 4, $249-257$. 


\section{Introduction}

One of the most striking and incompletely explained features of HIV epidemiology is the extent of the differential spread of HIV. Because that HIV entered different populations at different times, this differential spread is best evaluated by the peak prevalence that HIV attains in different populations around the world [1]. In the 149 countries for which UNAIDS has provided data, the peak HIV prevalence is less than 1\% in 98 countries (median HIV prevalence- $0.2 \%$ ), between $1 \%$ and $5 \%$ in 31 countries and $\geq 5 \%$ in 20 countries (median HIV prevalence-10.5\%) [2] [3].

A combination of biological, behavioral and network-level factors must be responsible for determining these differences. Various polymorphisms in HIV infectivity and human susceptibility have been discovered that could influence HIV spread, but their population distribution is unable to explain more than a small part of the differential spread of HIV [4]-[7]. Another biological factor which has been shown to influence the spread of HIV is the proportion of the population that has been circumcised [8] [9].

Individual-level factors have not been able to explain more than a part of the variation in HIV spread. Wellings et al. [10], reviewed sexual behavior around the world and concluded that the proportion of persons who reported 2 or more sexual partners in the past year was, if anything, higher in developed than in developing countries. Similarly, the prevalence of high-risk individual-level sexual behaviors was unable to explain the high HIV prevalence in sub Saharan Africa [11].

Differences in sexual-network-connectivity are increasingly appreciated as playing an important role in influencing the prevalence of STIs in particular communities [12] [13]. A number of ecological studies have shown that communities with high HIV prevalence have increased markers of sexual-network-connectivitysuch as the prevalence of sexual partner concurrency (sexual partnerships that overlap in time) [14]-[17]. Since networks are properties of populations, their effect on STI transmission operates at a population-level. It is thus appropriate and necessary to investigate the correlation between network-connectivity and HIV prevalence at an ecological level [15].

A number of ecological analyses have been performed and have found national HIV prevalence to be correlated with a wide variety of social, economic and behavioral variables [9] [18]-[20]. There are however a number of problems with these studies [1]. Firstly, no variables to measure sexual network connectivity were included in any of these studies. Secondly, the outcome variable, HIV prevalence, was either not determined from representative population samples [19], or it was taken from a particular year for all countries regardless of the stage of the countries epidemic [9] [18]. It has recently been demonstrated that there are a number of advantages to using national peak HIV prevalence over this single year sampling approach [17]. In particular, this approach is not affected by the stage at which an epidemic is when the sample is taken. Peak HIV prevalence is easily calculated from UNAIDS estimates of HIV seroprevalence samples from 148 countries for the years 1990-2009 [1] [21].

This study makes use of the availability of these advances in HIV epidemiology to evaluate the extent to which five key explanatory variables (circumcision prevalence, condom usage, STI treatment coverage, number of sex partners, partner concurrency) are correlated with peak HIV prevalence rates at national and world regional levels.

\section{Methodology}

National peak HIV prevalence rates for 15 - 49 years old were derived from a UNAIDS publication which provided estimated annual HIV prevalence for 148 countries from 1990 to 2009 [21].

\subsection{Explanatory Variables}

\subsubsection{Circumcision Data}

The national prevalence rates of male circumcision as of December 2006 were taken from a publication from the World Health Organization and Joint United Nations Programme on HIV/AIDS which estimated national circumcision prevalence rates [22]. Countries were classified as having circumcision prevalence rates $<20 \%$, 20\% - $80 \%$ or $>80 \%$. These estimates were based on Demographic and Health Survey data available or otherwise from other published sources [22]. In the case of five countries no data was available.

\subsubsection{STI Treatment}

There is little published data that compares the quality and accessibility of STI treatment by country. As a proxy 
for STI treatment quality, we used the estimated antiretroviral therapy (ART) coverage. National ART coverage is defined as the percentage of patients in 2009 who require ART (according to the WHO 2009 guidelines) who were receiving ART. These figures were obtained from the UNAIDS AIDS Report 2010 [21].

\subsubsection{Number of Sexual Partners and Condom Usage}

The percent of adults (25 - 49 years old) who had more than one sexual partner in the previous year by country was used as the number of sexual partners' variable. The indicator of condom usage chosen was the percentage of women and men aged 25 - 49 who had more than one sexual partner in the past 12 months who reported using a condom during their last sexual intercourse. The data for both these variables was extracted from the UNAIDS 2008 Report on global AIDS epidemic. This document summarized the data for these variables from all countries that had measured them in representative surveys (mainly Demographic and Health Surveys). We tabulated this data for all the countries of the world. If more than one survey was reported, we utilized the results from 2005 or the result closest to this year.

\subsubsection{Prevalence of Concurrent Partnering}

To overcome the problems of comparability with different datasets using different methodologies and definitions of concurrency, we used one of the only multinational surveys which assess concurrency using the same methodology. These are the WHO/Global Programme on AIDS (GPA) sexual behavioral surveys conducted in 1989/1990. All 11 countries that performed these surveys between 1989 and 1990 and asked questions about concurrency are evaluated here [23]. All these surveys followed WHO/GPA protocols. These included that national probability samples of the general populations aged 15 to 49 should be utilized. The variable for concurrency was derived from the question "Do you now have one or more than one spouse/regular partner?" The variable we used in our analysis was the percentage of men 15 - 49 years old who had more than one sexual partnership active at the time of the survey. The details of this analysis are presented more fully elsewhere [17].

\subsubsection{Regions}

Data were grouped into 9 geographic regions, based on groupings used by the WHO (see Appendix) [24]. The means/medians and ranges of the condom usage, number of partners and concurrency variables were calculated for each region. For the national ART coverage rates, only the absolute percentage coverage were presented in the source document and these are reported. The prevalence of circumcision by world is summarized by two variables - the percentage of countries in the region where circumcision prevalence is $\geq 20 \%$ and those where the prevalence is above $80 \%$.

\subsubsection{Statistical Analysis}

We calculated Spearman's correlation coefficient with 95\% confidence interval for the relationship between estimated peak HIV prevalence and each of the five explanatory variables. These correlations were performed at the global level. For the correlations of circumcision with HIV prevalence, each country was coded 1, 2 or 3 if circumcision prevalence was $<20 \%, 20 \%-80 \%$ or $>80 \%$ respectively. All analyses were performed in Stata 12.0 (College Station, TX).

\section{Results}

\subsection{Circumcision}

As shown in Table 1, at the global level there was no association between the prevalence rates of circumcision and peak HIV (rho $=0.118$; $\mathrm{P}=0.161$ ). When the analyses were stratified by world region, there was a strong correlation between circumcision and HIV prevalence in sub Saharan Africa (rho $=-0.659 ; \mathrm{P}=0.000$ ) and a correlation in the South/South East Asia region (rho $=-0.554 ; \mathrm{P}=0.026$ ). There was no significant correlation in any of the other regions. Sub Saharan Africa was found to have the second and third highest circumcision rates in the world when the circumcision prevalence thresholds were set at $80 \%$ and $20 \%$ respectively (see Table 2).

\subsection{STI Treatment, Number of Sex Partners \& Condom Usage}

There was no significant association between the number of sex partners in the previous year and HIV prevalence (rho $=0.134 ; \mathrm{P}=0.298$ ), condom usage and HIV prevalence (rho $=0.048 ; \mathrm{P}=0.794$ ) or STI treatment and 
Table 1. Spearman's correlation coefficients for the relationship between the independent variables and peak national adult HIV seroprevalence by country .

\begin{tabular}{|c|c|c|c|c|c|}
\hline & $\begin{array}{l}\text { Circumcision } \\
\text { prevalence }^{\mathrm{b}}\end{array}$ & $\begin{array}{l}\text { Antiretroviral } \\
\text { therapy coverage }^{\mathrm{c}}\end{array}$ & $\begin{array}{l}\text { More than one sex } \\
\text { partner in last year }{ }^{\mathrm{d}}\end{array}$ & $\begin{array}{l}\text { Condom usage } \\
(\% \text { at last sex })^{\mathrm{e}}\end{array}$ & $\begin{array}{l}\text { Point-prevalence of male } \\
\text { concurrency (15 - } 49 \text { years old) }\end{array}$ \\
\hline $\begin{array}{c}\text { Rho } \\
(95 \% \text { CI })\end{array}$ & $\begin{array}{c}0.118 \\
(-0.047-0.276)\end{array}$ & $\begin{array}{c}0.143 \\
(-0.045-0.322)\end{array}$ & $\begin{array}{c}0.134 \\
(-0.120-0.372)\end{array}$ & $\begin{array}{c}0.048 \\
(-0.236-0.325)\end{array}$ & $\begin{array}{c}0.853 \\
(0.517-0.961)\end{array}$ \\
\hline $\mathbf{P}$ & 0.161 & 0.136 & 0.298 & 0.794 & 0.001 \\
\hline $\mathbf{n}$ & 144 & 110 & 62 & 49 & 11 \\
\hline
\end{tabular}

${ }^{\mathrm{a}}$ See methods section for description of data sources; 'Spearman's correlation for circumcision prevalence was conducted for all 144 countries for which data was available and the countries were coded 1 , 2 or 3 if circumcision prevalence was $<20 \%, 20 \%-80 \%$ or $>80 \%$ respectively; ${ }^{\text {C }}$ The percentage of patients in 2009 who require ART (according to the WHO 2009 guidelines), who were receiving ART; ${ }^{\mathrm{d}}$ Percent of 25 - 49 men and women who had more than one sexual partner in the preceding year 2010; ${ }^{\text {e}}$ Percentage of women and men aged 25 - 49 who had more than one sexual partner in the past 12 months reporting the use of a condom during their last sexual intercourse.

Table 2. Prevalence of HIV and explanatory variables (circumcision, ART coverage, condom usage, and multiple partnering) by world regions.

\begin{tabular}{|c|c|c|c|c|c|c|c|c|}
\hline & 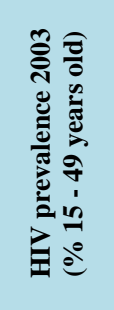 & 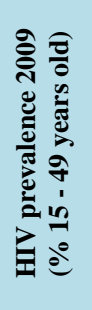 & 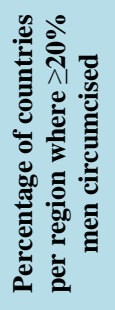 & 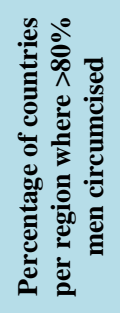 & 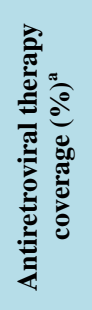 & 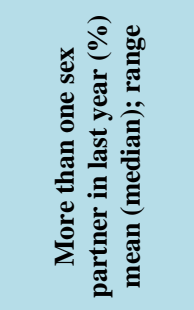 & 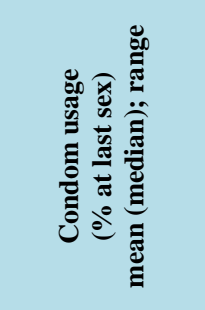 & 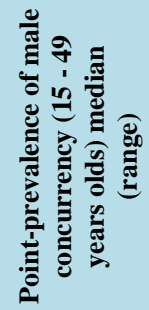 \\
\hline East Asia \& Pacific & $0.1-0.1$ & 0.1 & 11 & 11 & $39^{\mathrm{d}}$ & 15 (21); $14-54$ & b & \\
\hline North Africa \& Middle East & $0.2-0.4$ & 0.2 & 100 & 95 & 10 & $16(15) ; 6$ - 19 & c & \\
\hline Australia \& NZ & $0.1-0.1$ & 0.1 & 50 & 0 & & & - & \\
\hline Western Europe & $0.3-0.3$ & 0.2 & 19 & 0 & & 14 (16); 10 - 18 & $19(48) ; 5$ - 75 & \\
\hline North America & $0.5-0.7$ & 0.5 & 100 & 0 & & 13 (13); 13 & - & \\
\hline Eastern Europe \& Central Asia & $0.5-0.9$ & 0.8 & 10 & 26 & 23 & $14(13) ; 1$ - 41 & 68 (49); 28 - 77 & \\
\hline South \& South East Asia & $0.4-0.8$ & 0.3 & 6 & 37 & $39^{d}$ & $6(7) ; 1-14$ & $58(38) ; 0-66$ & $3(2-3)$ \\
\hline Latin America \& Caribbean & $0.5-3.1$ & 0.5 & 0 & 0 & 63 & $16(9) ; 2$ - 22 & 21 (27); 12 - 56 & $7(7-7)$ \\
\hline Sub Saharan Africa & $7.5-8.5$ & 5.0 & 81 & 66 & 49 & 8 (10); 2 - 43 & $26(31) ; 6-71$ & $20(13-55)$ \\
\hline
\end{tabular}

${ }^{\mathrm{a}}$ Data from USA, Canada, Western Europe, Australia, New Zealand and Russia not reported; ${ }^{\mathrm{b}}$ Data for single country reported—Palau (60\%); ${ }^{\mathrm{c}} \mathrm{Data}$ for single country reported-Turkey (45\%); ${ }^{\mathrm{d}}$ The data for South East Asia, South Asia and East Asia were only provided in aggregate for this combined region.

HIV prevalence (rho $=0.143 ; \mathrm{P}=0.136$ ). Stratification by world region had no effect on the relationship between peak HIV prevalence and STI treatment, number of sex partners or condom usage (data not shown). The prevalence of condom usage and adequate STI treatment was not lower in sub Saharan Africa (the highest HIV prevalence region). Neither was the number of sex partners higher in this region (Table 2).

\subsection{Prevalence of Concurrent Partnering}

There was a significant association between concurrency and peak HIV prevalence (rho $=0.853 ; \mathrm{P}=0.001$ ). This analysis was limited by the fact that the GPA survey contained only 11 countries.

\section{Discussion}

A first step in working out the determinants of a disease is mapping the distribution of the disease, its putative risk factors and seeing which factors are correlated [25] [26]. What does this analysis reveal as regards the widely divergent peak HIV prevalence around the world?

Low circumcision rates do not appear to be the dominant factor responsible. Our analysis confirms the find- 
ings of other studies that differential circumcision rates explain a significant part of the variation in HIV prevalence within African populations [9] [18] [27]. There was however no significant association found between peak HIV prevalence and circumcision prevalence globally. Of note, the sub Saharan African region has the second highest percentage of countries where more than $80 \%$ of men are circumcised in the world with the highest prevalence of HIV. Even in the countries of Western Africa with close to universal circumcision [22] [27], HIV prevalence rates are considerably higher than the low HIV prevalence world regions [21]. This patterning of the relationship between circumcision and HIV prevalence globally is possibly explained by the existence of some other factor that is driving the higher HIV prevalence rates in sub Saharan Africa and that circumcision is then moderating this effect. This explanation is strengthened by the fact that exactly the same relationship between circumcision and HIV prevalence exists in South Africa's ethnic groups. There is no correlation between HIV and circumcision prevalence by ethnic group when all 12 of South Africa's major ethnic groups are included in the analysis [28]. There is however a strong correlation when the analysis is restricted to the black ethnic groups. The non-black ethnic groups (white, colored, Indian) have both the lowest circumcision and HIV prevalence rates. As is the case with the global relationship, it appears that something else is driving the higher HIV prevalence within the high HIV prevalence groups and circumcision modifies this effect. What might this driver be?

Inadequate STI treatment is one of the explanations advanced in the literature [29]. Whilst an effective STI treatment capability may be important to HIV control, there is little evidence that we have been able to find, to suggest that this capability is poorer in the high HIV prevalence region of sub Saharan Africa as compared to other developing regions of the world [24]. It must be noted that ART coverage is not an optimal measure of STI treatment capability. Nonetheless, the provision of ART is arguably the most difficult STI treatment to administer and thus the indicator does provide some quantitative assessment of the extent to which countries and regions can provide STI services according to needs. According to the data presented here, there is no association between ART coverage and peak HIV prevalence. This may well be a misleading finding. For example, ART coverage in heavily HIV affected countries may benefit from the political mobilization that may follow noticeable epidemics. Of note, the UNAIDS report from which the ART coverage data is taken does not provide data for the low HIV prevalence regions of North America, Western Europe or Australasia. Other sources however suggest that ART coverage rates in these regions are high [30]. In the absence of other measures of STI treatment efficacy, all we may safely conclude from this data is that the high HIV prevalence region of sub Saharan Africa is clearly capable of delivering the most difficult STI therapies at scale.

Sexual behavior is one of the most varied of all human behaviors [31]. A priori, one would expect that the factors underpinning the regional variations in HIV rates would include both individual-level and population/ network-level determinants [12]. Our analysis included only two individual-level measures-condom usage and number of sexual partners in the prior 12 months. Neither of these was significantly associated with HIV prevalence.

STIs are transmitted over networks of sexual partnerships, and hence differences in the structure of these networks might be a determinant of differential STI spread [32]. The importance of these population-level characteristics is spelt out succinctly by Aral et al. "Whereas individual-level parameters may influence individuals in a given population acquire infection, it is population-level parameters that affect the presence and prevalence of infection to be acquired" [12]. Population-level parameters such as network structure may therefore explain why certain populations have high HIV prevalence rates despite having no measurable differences in the traditionally measured individual-level risk factors [14].

Thus at an individual level the total number of sexual partner one has had over a specified period is a well established risk factor for most STIs [33]. This is not clear as the case at a population level. If one compares the low and high HIV prevalence populations within the USA and South Africa, the high prevalence populations show little difference in lifetime number of partners, but their chance of contracting an STI if they have never engaged in a high risk activity is considerably higher than those in the low prevalence sub-popula- tions with the same risk behavior [14] [16]. In the USA, for example, a black woman who has one lifetime partner has four times higher chance of contracting HSV-2 than a white woman with one partner [34]. Differences in the structure of the racial sex networks have been shown to explain a large part of these racial differences in STI prevalence [14] [32]. One of the most important determinants of differences in sexual network connectivity has been shown to be the proportion of relationships which run concurrently, which is significantly higher in the high HIV prevalence populations in the USA and South Africa [14] [16]. 
There is a paucity of work done to compare the structures of sexual networks of different populations around the world [15]. In large part this may be due to a paucity of studies which collect comparable network level data from different international populations [15]. Our study suggests that differences in network connectivity may be an important determinant of international differences in HIV prevalence.

There are a number of limitations of our study. Chief amongst these is the quality of the data. As mentioned above, there is a lack of comparative sexual behavior data that includes key network-level attributes such as partner concurrency from countries around the world. As a result we were forced to use relatively small datasets such as the 11 countries in the GPA surveys to represent the concurrency. The low number of observations means that the 95\% confidence intervals for our Spearman's correlation coefficients are wide (see Table 1). The data used in our study were from a 19-year period, which is suboptimal. This may have compromised our primary aim, namely assessing the correlation between HIV prevalence and particular risk factors by country and region. The use of peak HIV prevalence as our outcome variable did however mitigate some of these problems. By its nature, peak HIV prevalence represents a composite measure of the accumulation of the various component causes of an HIV epidemic that operated over the previous ten years or longer [17]. As such, it is vital that the exposure variables used are representative of the time when they would have been likely to have exerted their greatest effect on HIV prevalence. In the case of the generalized HIV epidemics of sub Saharan Africa, the dates concurrency was measured. (1989/90) is a useful sampling time as this precedes the peak HIV prevalence of all the affected countries [1]. In addition, various lines of evidence suggest that the prevalence of concurrency in this region have persisted at these high levels for some time [35] [36].

Likewise, circumcision prevalence is likely to have been fairly stable over this time period [37]. The same may not however be the case with STI treatment capability, condom usage and number of sexual partners. There is evidence that all three of these have varied in response to the HIV epidemic and these changes could invalidate our methodology [38]. Furthermore, the study is an ecological one and its findings do not apply to different levels of aggregation. Whilst the ecological inference fallacy is a concern, it must also be borne in mind that attributes of networks cannot be reduced to those of individuals and thus ecological studies are necessary to fully characterize the determinants of variations in HIV prevalence [15].

HIV spread is determined by a complex interaction between social, behavioral, economic and biological factors operating at multiple levels. This analysis was limited to five proximal risk factors. Further ecological studies to assess the broader social and economic correlates of HIV prevalence using peak HIV prevalence as outcome variable are warranted.

\section{Acknowledgements}

Nil.

\section{Competing Interest}

None declared.

\section{Funding Statement}

This research received no specific grant from any funding agency in the public, commercial or not-for-profit sectors.

\section{References}

[1] Kenyon, C., Colebunders, R., Voeten, H. and Lurie, M. (2013) Peak HIV Prevalence: A Useful Outcome Variable for Ecological Studies. International Journal of Infectious Diseases, 17, e286-e288. http://dx.doi.org/10.1016/j.ijid.2012.12.020

[2] UNAIDS (2009) AIDS Epidemic Update. WHO Regional Office Europe.

[3] Kenyon, C. and Buyze, J. Should the Threshold for Generalized HIV Epidemics Be 1\% or 5\%? International Journal of STD AIDS. in press.

[4] Abu-Raddad, L.J., Barnabas, R.V., Janes, H., Weiss, H.A., Kublin, J.G., Longini Jr., I.M., Wasserheit, J.N. (2012) Have the Explosive HIV Epidemics in Sub-Saharan Africa Been Driven by Higher Community Viral Load? AIDS, 27, 981-989. 
[5] Gonzalez, E., Dhanda, R., Bamshad, M., Mummidi, S., Geevarghese, R., Catano, G., Anderson, S.A., Walter, E.A., Stephan, K.T., Hammer, M.F., et al. (2001) Global Survey of Genetic Variation in CCR5, RANTES, and MIP-1 Alpha: Impact on the Epidemiology of the HIV-1 Pandemic. Proceedings of the National Academy of Sciences of the United States of America, 98, 5199-5204. http://dx.doi.org/10.1073/pnas.091056898

[6] Gonzalez, E., Kulkarni, H., Bolivar, H., Mangano, A., Sanchez, R., Catano, G., Nibbs, R.J., Freedman, B.I., Quinones, M.P., Bamshad, M.J., et al. (2005) The Influence of CCL3L1 Gene-Containing Segmental Duplications on HIV1/AIDS Susceptibility. Science, 307, 1434-1440. http://dx.doi.org/10.1126/science.1101160

[7] Ramsuran, V., Kulkarni, H., He, W.J., Mlisana, K., Wright, E.J., Werner, L., Castiblanco, J., Dhanda, R., Le, T., Dolan, M.J., et al. (2011) Duffy-Null-Associated Low Neutrophil Counts Influence HIV-1 Susceptibility in High-Risk South African Black Women. Clinical Infectious Diseases, 52, 1248-1256. http://dx.doi.org/10.1093/cid/cir119

[8] Auvert, B., Buve, A., Lagarde, E., Kahindo, M., Chege, J., Rutenberg, N., Musonda, R., Laourou, M., Akam, E., Weiss, H.A., et al. (2001) Male Circumcision and HIV Infection in Four Cities in Sub-Saharan Africa. AIDS, 15, S31-S40. http://dx.doi.org/10.1097/00002030-200108004-00004

[9] Drain, P.K., Halperin, D.T., Hughes, J.P., Klausner, J.D. and Bailey, R.C. (2006) Male Circumcision, Religion, and Infectious Diseases: An Ecologic Analysis of 118 Developing Countries. BMC Infectious Diseases, 6, 172. http://dx.doi.org/10.1186/1471-2334-6-172

[10] Wellings, K., Collumbien, M., Slaymaker, E., Singh, S., Hodges, Z., Patel, D. and Bajos, N. (2006) Sexual Behaviour in Context: A Global Perspective. The Lancet, 368, 1706-1728. http://dx.doi.org/10.1016/S0140-6736(06)69479-8

[11] Auvert, B., Buve, A., Ferry, B., Carael, M., Morison, L., Lagarde, E., Robinson, N.J., Kahindo, M., Chege, J., Rutenberg, N., et al. (2001) Ecological and Individual Level Analysis of Risk Factors for HIV Infection in Four Urban Populations in Sub-Saharan Africa with Different Levels of HIV Infection. AIDS, 15, S15-S30. http://dx.doi.org/10.1097/00002030-200108004-00003

[12] Aral, S.O., Lipshutz, J. and Blanchard, J. (2007) Drivers of STD/HIV Epidemiology and the Timing and Targets of STD/HIV Prevention. Sexually Transmitted Infections, 83, i1- i4. http://dx.doi.org/10.1136/sti.2007.027169

[13] Morris, M. and Epstein, H. (2011) Role of Concurrency in Generalised HIV Epidemics. The Lancet, 378, $1843-1844$. http://dx.doi.org/10.1016/S0140-6736(11)61803-5

[14] Morris, M., Kurth, A.E., Hamilton, D.T., Moody, J. and Wakefield, S. (2009) Concurrent Partnerships and HIV Prevalence Disparities by Race: Linking Science and Public Health Practice. American Journal of Public Health, 99, 1023-1031. http://dx.doi.org/10.2105/AJPH.2008.147835

[15] Morris, M., Epstein, H. and Wawer, M. (2010) Timing Is Everything: International Variations in Historical Sexual Partnership Concurrency and HIV Prevalence. PLoS One, 5, e14092. http://dx.doi.org/10.1371/journal.pone.0014092

[16] Kenyon, C., Dlamini, S., Boulle, A., White, R.G. and Badri, M. (2009) A Network-Level Explanation for the Differences in HIV Prevalence in South Africa's Racial Groups. African Journal of AIDS Research, 8, 243-254. http://dx.doi.org/10.2989/AJAR.2009.8.3.1.922

[17] Kenyon, C. and Colebunders, R. (2012) Strong Association between Point-Concurrency and National Peak HIV Prevalence. International Journal of Infectious Diseases, 16, e826-e827. http://dx.doi.org/10.1016/j.ijid.2012.05.008

[18] Drain, P.K., Smith, J.S., Hughes, J.P., Halperin, D.T. and Holmes, K.K. (2004) Correlates of National HIV Seroprevalence: An Ecologic Analysis of 122 Developing Countries. JAIDS: Journal of Acquired Immune Deficiency Syndromes, 35, 407-420. http://dx.doi.org/10.1097/00126334-200404010-00011

[19] Over, M. (1998) The Effects of Societal Variables on Urban Rates of HIV Infection in Developing Countries: An Exploratory Analysis. Confronting AIDS: Evidence from the Developing World Brussels and Washington DC, European Commission and World Bank.

[20] Sawers, L. and Stillwaggon, E. (2010) Understanding the Southern African “Anomaly”: Poverty, Endemic Disease and HIV. Development and Change, 41, 195-224. http://dx.doi.org/10.1111/j.1467-7660.2010.01639.x

[21] UNAIDS (2010) Report on the Global AIDS Epidemic 2010. UNAIDS, Geneva.

[22] Weiss, H. (2008) Male Circumcision: Global Trends and Determinants of Prevalence, Safety, and Acceptability. World Health Organization.

[23] Carael, M. (1995) Sexual Behaviour. In: Cleland, J.G. and Ferry, B., Eds., Sexual Behaviour and AIDS in the Developing World, Taylor \& Francis, London, 75-123.

[24] Gerbase, A, Rowley, J., Heymann, D., Berkley, S. and Piot, P. (1998) Global Prevalence and Incidence Estimates of Selected Curable STDs. Sexually Transmitted Infections, 74, 12.

[25] Reingold, A.L. (1998) Outbreak Investigations-A Perspective. Emerging Infectious Disease, 4, 21. http://dx.doi.org/10.3201/eid0401.980104

[26] De Schryver, A. and Meheus, A. (1990) Epidemiology of Sexually Transmitted Diseases: The Global Picture. Bulletin 
of the World Health Organization, 68, 639.

[27] Auvert, B., Buve, A., Lagarde, E., Kahindo, M., Chege, J., Rutenberg, N., Musonda, R., Laourou, M., Akam, E. and Weiss, H. (2001) Male Circumcision and HIV Infection in Four Cities in Sub-Saharan Africa. Aids, 15, S31-S40. http://dx.doi.org/10.1097/00002030-200108004-00004

[28] Kenyon, C. (2013) Association of HIV Prevalence and Concurrency of Sexual Partnerships in South Africa's Language Groups: An Ecological Analysis. Southern African Journal of HIV Medicine, 14, 25-28.

[29] Aral, S.O., Over, M., Manhart, L. and Holmes, K.K. (2006) Sexually Transmitted Infections. In: Jamison, D.T. and Mosley, W.H., Eds., Disease Control Priorities in Developing Countries: Health Policy Responses to Epidemiological Change, World Bank, Washington DC, 653-689.

[30] Cohen, S.M., Van Handel, M.M., Branson, B.M., Blair, J.M., Hall, H.I., Hu, X.H., Koenig, L.J., Skarbinski, J., Tracey, A., Mermin, J., et al. (2012) HIV Prevention Through Care and Treatment. JAMA, 307, 247-250.

[31] Youm, Y. and Paik, A. (2004) The Sex Market and Its Implications for Family Formation. In: Laumann, E., Ellingson, S., Mahay, J., Paik, A. and Youm, Y., Eds., The Sexual Organization of the City, University of Chicago Press, Chicago, 165-193.

[32] Laumann, E.O. and Youm, Y. (1999) Racial/Ethnic Group Differences in the Prevalence of Sexually Transmitted Diseases in the United States: A Network Explanation. Sexually Transmitted Diseases, 26, 250-261. http://dx.doi.org/10.1097/00007435-199905000-00003

[33] Gross, G. and Tyring, S.K. (2011) Sexually Transmitted Infections and Sexually Transmitted Diseases. Springer Verlag, Heidelberg. http://dx.doi.org/10.1007/978-3-642-14663-3

[34] Fleming, D.T., McQuillan, G.M., Johnson, R.E., Nahmias, A.J., Aral, S.O., Lee, F.K. and St. Louis, M.E. (1997) Herpes Simplex Virus Type 2 in the United States, 1976 to 1994. The New England Journal of Medicine, 337, 1105-1111. http://dx.doi.org/10.1056/NEJM199710163371601

[35] Maughan-Brown, B. (2013) Concurrent Sexual Partnerships among Young Adults in Cape Town, South Africa: How Is Concurrency Changing? Sexual Health, 10, 246-252.

[36] Kenyon, C. and Zondo, S. (2011) Why Do Some South African Ethnic Groups Have Very High HIV Rates and Others Not? African Journal of AIDS Research, 10, 51-62. http://dx.doi.org/10.2989/16085906.2011.575548

[37] World Health Organization (2007) Male Circumcision: Global Trends and Determinants of Prevalence, Safety and Acceptability. World Health Organization, Geneva.

[38] Kirby, D. (2008) Changes in Sexual Behaviour Leading to the Decline in the Prevalence of HIV in Uganda: Confirmation from Multiple Sources of Evidence. Sexually Transmitted Diseases, 84, ii35-ii41. 


\section{Appendix}

\section{Box 1. Listing of Countries in Each of 9 World Regions}

\section{Australia and New Zealand}

Australia, New Zealand

Eastern Asia \& Pacific

Brunei Darussalam, China, Democratic People’s Republic of Korea, Japan, Mongolia, Republic of Korea, Singapore, Cook Islands, Fiji, Kiribati, Marshall Islands, Micronesia (Federated States of), Nauru, Niue, Palau, Papua New Guinea, Samoa, Solomon Islands, Tonga, Tuvalu, Vanuatu

\section{East Europe and central Asia}

Albania, Armenia, Azerbaijan, Belarus, Bosnia and Herzegovina, Bulgaria, Croatia, Czech Republic, Estonia, Georgia, Hungary, Kazakhstan, Kyrgyzstan, Latvia, Lithuania, Moldova, Montenegro, Poland, Romania, Russian Federation, Serbia, Slovakia, Tajikistan, The former Yugoslav Republic of Macedonia, Turkey, Turkmenistan, Ukraine, Uzbekistan

\section{Latin America and the Caribbean}

Antigua and Barbuda, Argentina, Bahamas, Barbados, Belize, Bolivia, Brazil, Chile, Colombia, Costa Rica, Cuba, Dominica, Dominican Republic, Ecuador, El Salvador, Grenada, Guatemala, Guyana, Haiti, Honduras, Jamaica, Mexico, Nicaragua, Panama, Paraguay, Peru, Saint Kitts and Nevis, Saint Lucia, Saint Vincent and the Grenadines, Suriname, Trinidad and Tobago, Uruguay, Venezuela (Bolivarian Republic of)

\section{North Africa and Middle East}

Algeria, Bahrain, Cyprus, Djibouti, Egypt, Iran (Islamic Republic of), Iraq, Israel, Jordan, Kuwait, Lebanon, Libyan Arab Jamahiriya, Malta, Morocco, Oman, Qatar, Saudi Arabia, Syrian Arab Republic, Tunisia, United Arab Emirates, Yemen

\section{North America}

Canada, United States of America

\section{South Asia \& South-east Asia}

Afghanistan, Bangladesh, Bhutan, India, Maldives, Nepal, Pakistan, Sri Lanka, Cambodia, Indonesia, Lao People’s Democratic Republic, Malaysia, Myanmar, Philippines, Thailand, Timor-Leste, Viet Nam

\section{Sub-Saharan Africa}

Angola, Benin, Botswana, Burkina Faso, Burundi, Cameroon, Cape Verde, Central African Republic, Chad, Comoros, Congo, Côte d'Ivoire, Democratic Republic of the Congo, Equatorial Guinea, Eritrea, Ethiopia, Gabon, Gambia, Ghana, Guinea, Guinea-Bissau, Kenya, Lesotho, Liberia, Madagascar, Malawi, Mali, Mauritania, Mauritius, Mozambique, Namibia, Niger, Nigeria, Rwanda, Sao Tome and Principe, Senegal, Seychelles, Sierra Leone, Somalia, South Africa, Sudan, Swaziland, Togo, Uganda, United Republic of Tanzania, Zambia, Zimbabwe

\section{Western Europe}

Andorra, Austria, Belgium, Denmark, Finland, France, Germany, Greece, Iceland, Ireland, Italy, Luxembourg, Monaco, Netherlands, Norway, Portugal, San Marino, Slovenia, Spain, Sweden, Switzerland, United Kingdom 
Scientific Research Publishing (SCIRP) is one of the largest Open Access journal publishers. It is currently publishing more than 200 open access, online, peer-reviewed journals covering a wide range of academic disciplines. SCIRP serves the worldwide academic communities and contributes to the progress and application of science with its publication.

Other selected journals from SCIRP are listed as below. Submit your manuscript to us via either submit@scirp.org or Online Submission Portal.
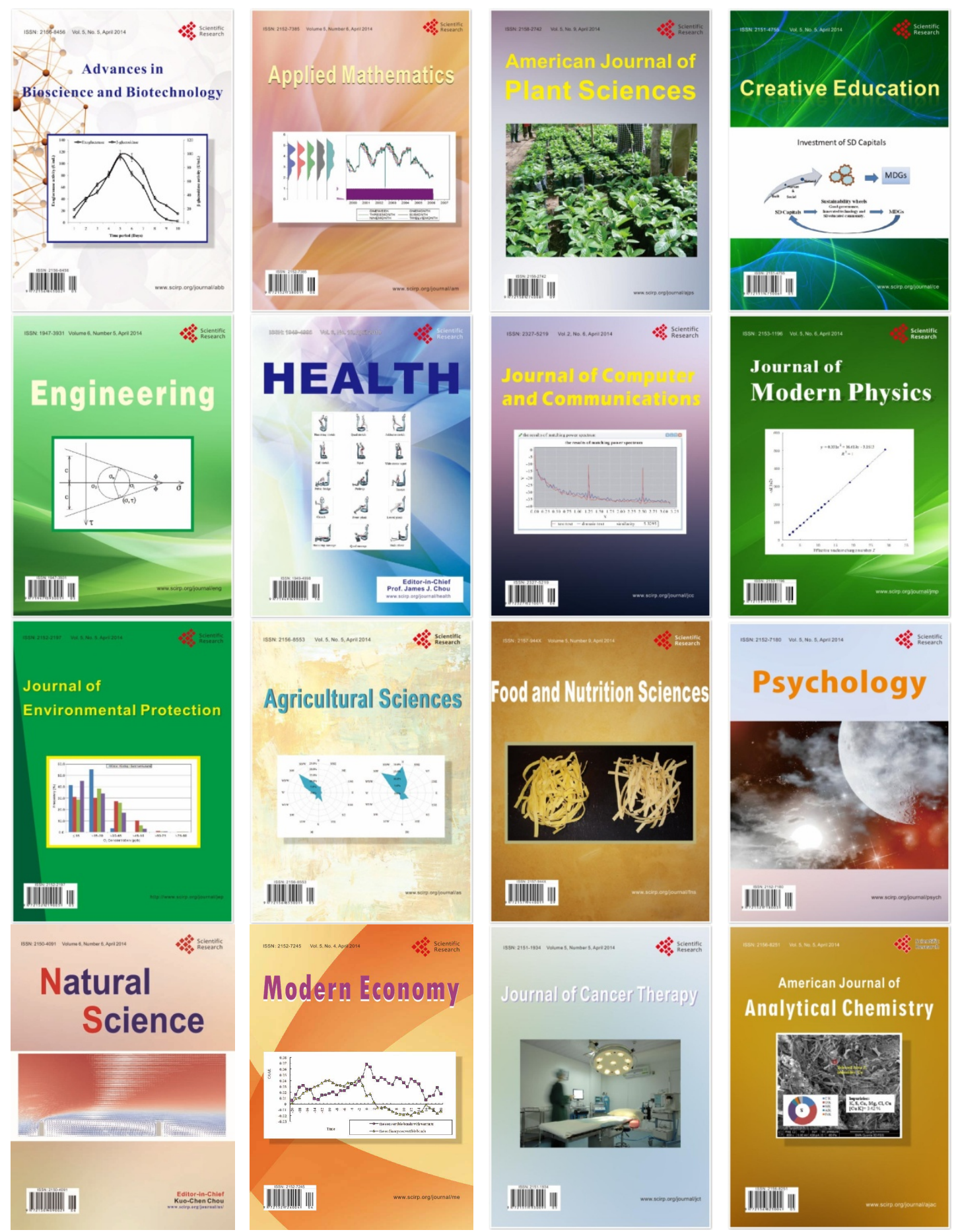